\title{
Multivitamins, folate, and colon cancer
}

Giovannucci E, Stampfer MJ, Colditz GA, et al. Multivitamin use, folate, and colon cancer in women in the Nurses' Health Study. Ann Intern Med 1998;129:51724.

\section{Background}

A low folate intake may lead to reduced DNA methylation, resulting in abnormalities in DNA synthesis and repair, which could contribute to colonic carcinogenesis. There is evidence from prospective cohort studies that folate deficiency increases the risk of colon cancer in men, but such data are lacking for women.

\section{Aim}

To determine whether dietary folate and folate from supplements protects against colon cancer in women.

\section{Design}

A prospective cohort investigation.

\section{Subjects}

88756 registered female nurses in the United States aged 30-55 years (Nurses' Health Study).

\section{Methods}

Subjects completed semiquantitative food frequency questionnaires which included information on 61 foods and beverages plus vitamin and mineral supplements. The cohort was followed up for the development of colon cancer. Cases were identified through follow up questionnaires and the United States National Death Index. Relative risks were calculated and adjusted for energy intake, age, family history of colorectal cancer, aspirin, smoking, body mass, and intake of red meat, fibre, and methionine.

\section{Results}

Follow up of the cohort was almost complete (96\%) and 442 new cases of colon adenocarcinoma were identified. Higher adjusted total folate intake was related to a lower risk for colon cancer $(\mathrm{RR}=0.69,95 \% \mathrm{CI}=0.52$ 0.93 ) for intake of $>400 \mu \mathrm{g} /$ day compared with $<200$ $\mu \mathrm{g} /$ day. Folate intake from dietary sources alone was related to a modest risk reduction and women who used supplements for 15 years or more had a marked reduction $(\mathrm{RR}=0.25,95 \% \mathrm{CI}=0.13-0.51)$.

\section{Conclusions}

A high dietary folate intake and long term folate supplementation may reduce the risk of colon cancer.

\section{Comment}

Case control and cohort studies consistently suggest that high intakes of vegetables are associated with a decreased risk of colorectal cancer ${ }^{1}$ but the specific nutrients involved have not been identified. Interest in the possible aetiological importance of folate has been stimulated by observa- tions suggesting that hypomethylation of DNA is an early step in colorectal carcinogenesis and by evidence of a positive association with alcohol, which has an adverse effect on folate metabolism. ${ }^{2}$

Giovannucci and colleagues ${ }^{3}$ provide evidence of an inverse association between folate intake and colon cancer. Compared with women whose intake was $\leqslant 200 \mu \mathrm{g} / \mathrm{day}$, the relative risk of colon cancer associated with an intake of $201-300 \mu \mathrm{g} /$ day was 0.9 , with an intake of $301-400 \mu \mathrm{g} /$ day it was 0.8 , and with an intake $>400 \mu \mathrm{g} /$ day it was 0.7 ( $\mathrm{p}$ for trend=0.01). There was no evidence of confounding. Among women with the highest category of intake, $86.3 \%$ used multivitamin supplements. The other three categories reflect primarily dietary sources. The inverse relationship with folate persisted when adjustment was made for other nutrients present in multivitamin supplements. Analysis of duration of use of multivitamins containing folic acid showed that the inverse relationship was apparent only after at least five years of use and the most marked effect was after at least 15 years of use.

Data from four other cohorts, one in women ${ }^{4}$ and three in men, ${ }^{5-7}$ suggest that there are weak inverse associations between colon cancer and reported intake of folate, or levels in serum or plasma. In general, case control studies are compatible with this, ${ }^{8}$ but the inverse relationship is not statistically significant after adjustment for other nutrients. In some of the studies the relationship was apparent only in women or was stronger in women than in men.

There may be substantial error in the assessment of dietary folate intake. ${ }^{2}$ As a consequence, misclassification is likely to have occurred in both cohort and case control studies. However, this would tend to attenuate any association towards the null.

No association between rectal cancer and long term multivitamin use was found in the cohort of Giovannucci and colleagues. ${ }^{3}$ Other studies of rectal cancer are inconsistent. They lack statistical power or may have selection bias.

Studies of colorectal adenomas can provide information about the earlier stages of the adenoma-carcinoma sequence. There is a consistent inverse association between adenomas and both dietary folate and red cell folate. ${ }^{8}$ This appears to be stronger than for colorectal cancer.

An intriguing aspect is gene-nutrient interaction. There is some evidence of interaction between MTHFR genotype and intake of folate and related nutrients, and perhaps alcohol. ${ }^{7-11}$ In the presence of gene-environment interaction, failure to take both sets of factors into account may result in bias in the estimate of the relative risk. ${ }^{12}$

In conclusion, the possibility that the inverse relationship between folate and colonic neoplasia is a result of uncontrolled confounding from other nutrients cannot entirely be excluded. Only a randomised controlled trial could resolve this issue. Clarification of the relationship between folate and rectal cancer, possible gender effects, the possible role of other genetic polymorphisms affecting folate metabolism and of mechanisms underlying apparent interactions between intake of folate and related nutrients, and the genes influencing folate metabolism would inform 
the trial design. The study of Giovannucci and colleagues ${ }^{3}$ suggests that prolonged high levels of folate intake may be necessary to prevent colon cancer. This raises questions about the feasibility of a trial and possible toxicity. In addition, the potential role of folate in the prevention of colon cancer should not be considered in isolation from the prevention of other disorders.

J LITTLE

Epidemiology Group, Department of Medicine and Therapeutics, University of Aberdeen, Foresterhill House Annexe, Foresterhill, Aberdeen AB25 2ZD, UK j.little@abdn.ac.uk

1 World Cancer Research Fund in Association with American Institute for Cancer Research. Food, Nutrition and the Prevention of Cancer: a global perspective. Menasha: American Institute for Cancer Research, 1997.

2 Herbert V. Recommended dietary intakes (RDI) of folate in humans. Am $\mathcal{f}$ Clin Nutr 1987;45:661-70.

3 Giovannucci E, Stampfer MJ, Colditz GA, et al. Multivitamin use, folate, and colon cancer in women in the Nurses' Health Study. Ann Intern Med 1998;129:517-24
4 Kato I, Dnistrian AM, Schwartz M, et al. Serum folate, homocysteine and colorectal cancer risk in women: a nested case-control study. Br f Cancer 1999;79:1917-21.

5 Giovannucci E, Rimm EB, Ascherio A, et al. Alcohol, low-methionine - lowfolate diets, and risk of colon cancer in men. $\mathcal{F}$ Natl Cancer Inst 1995;87:265-73.

6 Glynn SA, Albanes D, Pietinen P, et al. Colorectal cancer and folate status: a nested case-control study among male smokers. Cancer Epidemiol Biomarkers Prev 1996;5:487-94.

7 Ma J, Stampfer MJ, Giovannucci E, et al. Methylenetetrahydrofolate reductase polymorphism, dietary interactions and risk of colorectal cancer. Cancer Res 1997;57:1098-102.

8 Little J. Problems and approaches in investigating the role of micronutrients in the aetiology of cancer in humans. Br Med Bull 1999;55:600-18.

9 Chen J, Giovannucci E, Kelsy K, et al. A methylenetetrahydrofolate reductase polymorphism and the risk of colorectal cancer. Cancer Res 1996;56:4862-4.

10 Slattery ML, Potter JD, Samowitz W, et al. Methylenetetrahydrofolate reductase, diet, and risk of colon cancer. Cancer Epidemiol Biomarkers Prev 1999;8:513-18.

11 Ulrich CM, Kampman E, Bigler J, et al. Colorectal adenomas and the C677T MTHFR polymorphism: evidence for gene-environment interaction. Cancer Epidemiol Biomarkers Prev 1999;8:659-68.

12 Khoury MJ, Stewart W, Beaty TH. The effect of genetic susceptibility on causal inference in epidemiologic studies. Am f Epidemiol 1987;126:561-7. 